\title{
SOCIOCULTURAL AND INTERACTIONIST APPROACHES TO SECOND LANGUAGE ACQUISITION: ARE THEY COMPATIBLE?
}

\author{
Richard S. Lavin \\ Department of English Language \& Literature, Prefectural University of Kumamoto (Japan)
}

\begin{abstract}
Second/foreign language research within the sociocultural-theoretic (SCT) tradition has tended to proceed orthogonally to that in the more conventional interactionist paradigm. SCT researchers, although of course broadly interested in progress in the language in the same way as interactionist researchers are, in practice tend to ask different questions and to use different methods to obtain answers to them. Since the goals of educators with an SCT orientation and those with an interactionist orientation are at least similar, and the phenomena involved in people learning/acquiring/developing in a language are presumably the same whatever the theoretical terms used to describe them, this author suggests that there is a need for a unified account that allows constructs like the zone of proximal development (ZPD; Vygotsky, 1978), on the one hand, and interlanguage (Selinker, 1972), on the other, to be seen in terms of each other. This paper is intended as a small step towards constructing such an account.

Beginning with diagrammatic representations of the ZPD developed by the author and a colleague (Lavin \& Nakano, 2017) in an attempt to clarify the spatial nature of the ZPD, this paper will explore how the ZPD could potentially be spelled out in more concrete terms and reconciled with the concept of interlanguage. Further, leveraging the concept of imitation frequently appealed to in SCT, it will be suggested that development could be operationalised in terms of a learner's performance in a range of linguistic output activities, and the outline of such an approach is sketched out.
\end{abstract}

Keywords: Zone of proximal development, sociocultural theory, interactionist approach, imitation, interlanguage.

\section{Introduction}

Second/foreign language research within the sociocultural-theoretic (SCT) tradition has tended to proceed orthogonally to that in the more conventional interactionist paradigm. SCT researchers, although of course broadly interested in progress in the language in the same way as interactionist researchers are, in practice tend to ask different questions and to use different methods to obtain answers to them.

This is illustrated neatly in a well-known edited volume on second language acquisition (SLA) theories (VanPatten \& Williams, 2007b). The editors start (VanPatten \& Williams, 2007a) by stating ten observed phenomena that they believe an ideal theory of second language acquisition should explain (pp. 9-12). Those observations are:

1. Exposure to input is necessary for SLA;

2. A good deal of SLA happens incidentally;

3. Learners come to know more than what they have been exposed to in the input;

4. Learner's [sic] output (speech) often follows predictable paths with predictable stages in the acquisition of a given structure;

5. Second language learning is variable in its outcome;

6. Second language learning is variable across linguistic subsystems;

7. There are limits on the effects of frequency on SLA;

8. There are limits on the effect [sic] of a learner's first language on SLA;

9. There are limits on the effects of instruction on SLA;

10. There are limits on the effects of output (learner production) on language acquisition.

Theories and approaches addressed in VanPatten and Williams (2007b), generally a chapter at a time, are behaviorism, Monitor Theory, Universal Grammar, the concept-oriented approach (as an example of functionalist approaches), the Associative-Cognitive CREED, skill acquisition theory, Input Processing, Processability Theory, Autonomous Induction Theory, the interaction approach, and sociocultural theory. 
Each chapter in the volume follows a similar format, concluding with a section where (a subset of) the observations are repeated, and it is explained in what way the theory or approach addresses the observation.

Not all the theories or approaches claim to be complete models of second language acquisition; for example, Input Processing simply "aims to be a model of what happens during comprehension that may subsequently affect or interact with other processes"; thus, it is relevant only to five of the 10 observations above, and the remainder are not mentioned in the concluding section of that chapter. In fact, with the exception of the Associative-Cognitive CREED, none of the theories and approaches even attempts to account for all 10 of the observations. Nevertheless, reading through the volume, it is apparent that most authors accept the general veracity of the observations as well as the general terms of reference, notwithstanding some differences in emphasis.

Lantolf and Thorne's (2007) answers, however, are full of redefinitions and qualifications where they do not actually contradict the observations.

Under Observation 1 ("Exposure to input is necessary for SLA"), for example, they avoid using the term "input", stating that "participation in culturally organized activity is essential for learning to happen." They go on to mention that, in addition to interaction with others, "the artifacts that others have produced" are also important. They also mention "vicarious" participation (Ohta, 2001), imitation through private speech of others' linguistic behaviour.

Under Observation 2 ("A good deal of SLA happens incidentally"), they start by saying that "a bit of clarification is in order," and argue that "what is called incidental learning is not really incidental." Their argument hinges on the idea of goals and subgoals: While learning a dialogue, or learning a set of useful expressions, for example, may not be a higher goal of a learner, it may be a legitimate subgoal which, in combination with other subgoals, leads him/her towards a higher goal, for example being able to hold an extended conversation with a native speaker.

Under Observation 8 ("There are limits on the effect of a learner's first language on SLA"), Lantolf and Thorne say that "L1 meanings continue to have a pervasive effect in the L2 learning." Likewise, regarding Observation 9 ("There are limits on the effects of output (learner production) on language acquisition"), Lantolf and Thorne cite research by Merrill Swain and others showing that "social speech produced in the L1 and the L2 also impacts on L2 learning" (p. 219).

From the above, it is clear that ideas that are considered to constitute a broad consensus in mainstream SLA sit rather uncomfortably within an SCT framework. In what follows, I shall sketch an outline of how one part of a mainstream SLA framework, interlanguage, could be reframed in terms of the SCT notion of the zone of proximal development (ZPD). The structure of the remainder of the paper is as follows: After a brief description of the concepts of interlanguage and of the ZPD, I show how the ZPD can be represented diagrammatically. Finally, I show how ideas from processability theory (Pienemann, 1998, 2009) could be mapped onto such a representation.

\section{Interlanguage}

Interlanguage is a term coined by Larry Selinker (1972) to explain the insight that the target language (L2) system within a successful language learner's head cannot have been taught to the learner in any complete sense, since the amount of knowledge, much of it implicit, possessed by any fluent speaker is too large to be taught. Thus, the language system must have in an important sense been created by the learner anew, based on inputs from the learner's L2 linguistic environment. The nature of that internal system at any given time can be called that learner's interlanguage. For Selinker, part of the proper focus of SLA would be to describe the nature of that interlanguage and, rather than describing a learner's L2 talk and writing as a jumble of errors, viewing it "as being highly systematic and, thus being emblematic of complex acquisitional and developmental processes" (Selinker, 2014, p. 222).

A goal of the interlanguage research programme is to describe development in learners' capabilities in terms of interlinguistic change. However, it is a feature of much research in an interlanguage framework that changes are described in their own terms, sandwiched between references to the notion of interlanguage, but the specific changes and the putative interlanguage systems are rarely linked in any systematic way. There is still little in the way of an overall picture either of a specific interlanguage at any point in time or of an interlanguage developing over time.

\section{The zone of proximal development}

The Zone of Proximal Development (ZPD) is often defined as "the distance between the actual development level as determined by independent problem solving and the level of potential development as determined through problem solving under adult guidance" (Vygotsky, 1978, p. 86). The notion is these days frequently appealed to in language teaching/learning research. In many cases, the ZPD is appealed to 
as the general framework within which the research is occurring, and the specific findings are outlined, but the relationship between those findings and the framework is not spelled out, except in the general sense that guidance given was sensitive to perceived learner strengths and needs. In other words, we rarely get a clear specification of what (in the author's view) the ZPD of the learners was before the intervention discussed and to what extent the knowledge/skills/abilities gained as a result of the intervention were maximized, i.e. encompassed the whole of the (previous) ZPD.

\section{Clarifying the spatial metaphor of the ZPD}

Pointing out that reference to the one-dimensional concept of "distance" within the traditional definition of the ZPD is not really compatible with the two- or three-dimensional notion of zone, Lavin and Nakano (2017) suggest that a ZPD needs to be represented with some internal structure (see Fig. 1) to be very useful for descriptions of skills and the effects of interventions, considering (a) that much work within a ZPD framework is focused on microgenetic change; and (b) that a single, short intervention is unlikely to effect movement from, say, a "can barely do with copious support" state to full internalization. A major attraction of SCT is that it can capture development that may not be reflected in test scores; thus, it is important that our diagrammatic representations of the concept can show changes of a smaller nature. Guk and Kellogg (2007) give an apt example of why that might be necessary when they observe that, in an interactive classroom, teacher-fronted talk tends to be located near the outer boundary of the ZPD while student collaboration talk tends to be located nearer the inner boundary.

Figure 1. A schematic of the ZPD, incorporating the notion of different areas within the zone denoting things that are close to being internalized and those that can only barely be done with help.

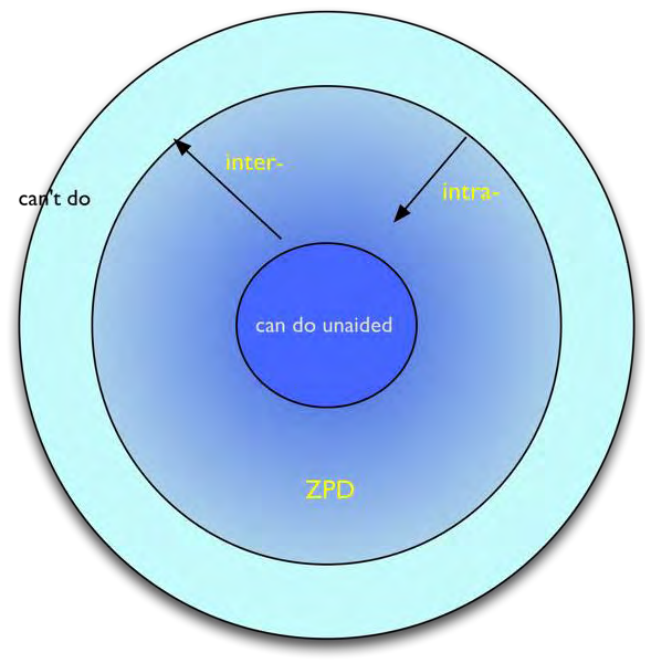

Figure 1 uses colour gradation to suggest that the outer and inner parts of the ZPD are different but is agnostic with regard to details of the internal structure, e.g. how many areas or sub-zones should be shown. It seems unlikely that it would be possible even in principle to determine objectively a "correct" answer to this question. But it seems reasonable for researchers to show as many such sub-zones as their findings, filtered through their theoretical viewpoints, tacitly assume. For example, Aljaafreh \& Lantolf's (1994) pioneering study on ZPD-sensitive L2 writing tuition uses the "regulatory framework" shown in Fig. 2 to show support designed to be the minimum necessary for the capabilities of a specific learner with regard to a specific error. This scale is described operationally and is used to diagnose a learner as being at one of five levels posited by the authors. In turn, those levels are conceptualized as representing three stages: other-regulation, partial self-regulation, and self-regulation. In the paper, the authors make reference to some errors being "high in ZPD" and others as being "low in the ZPD". The former could fairly be represented in the innermost part of the ZPD in Fig. 1, the latter in the outermost part, with a middle sub-zone showing features for which partial self-regulation has been achieved. 
Figure 2. Regulatory Scale - Implicit (strategic) to Explicit (slightly adapted from Aljaafreh \& Lantolf, 1994).

o. Tutor asks the learner to read, find the errors, and correct them independently, prior to the tutorial.

1. Construction of a "collaborative frame" prompted by the presence of the tutor as a potential dialogic partner.

2. Prompted or focused reading of the sentence that contains the error by the learner or the tutor.

3. Tutor indicates that something may be wrong in a segment (e.g., sentence, clause, line) -

"Is there anything wrong in this sentence?"

4. Tutor rejects unsuccessful attempts at recognizing the error.

5. Tutor narrows down the location of the error, repeating or pointing to the specific segment which contains the error.

6. Tutor indicates the nature of the error, but does not identify it

(e.g., "There is something wrong with the tense marking here").

7. Tutor identifies the error ("You can't use an auxiliary here").

8. Tutor rejects learner's unsuccessful attempts at correcting the error.

9. Tutor provides clues to help the learner arrive at the correct form (e.g., "It is not really past but something that is still going on").

10. Tutor provides the correct form.

11. Tutor providers some explanation for use of the correct form.

12. Tutor provides examples of the correct pattern when other forms of help fail to produce an appropriate responsive action.

\section{Mapping interlanguage onto a ZPD framework}

Let us take a look at an actual theory of interlanguage development and how it could be represented in terms of the ZPD. Processability Theory (PT; Pienemann, 1998, 2009) proposes that there are specific universal stages in the development of L2 syntactic ability, and that it is possible to diagnose from learners' (unplanned, spoken) production what stage they are at. To a large extent, the stages are defined in terms of the size of the domain within which information can be exchanged; thus, number marking within a phrase such as "two books" is less advanced than number marking in a sentence such as "He speaks". The framework is used to explain observed developmental sequences such as the following (Pienemann, 2009, p. 14) for question formation:

Stage 1: He live here? (SVO Question)

Stage 2: Where he is? (WH+SVO)

Stage 3: Where is he? (Copula Inversion)

Stage 4: Where has he been? (Aux-second)

(Note that the question listed in Stage 3 is a correct target form, but a learner at this stage could not produce correctly a question like the one shown in Stage 4.).

If we attempt to map this onto a ZPD framework, in the case of a learner who is considered to be at Stage 2, we come up with something like what is shown in Fig. 3. Stage 1 is already fully internalized and is therefore not part of the ZPD. Stage 2 can benefit from various kinds of teaching to increase automatization and confidence and is therefore by definition part of the ZPD. Stage 3 is the next stage, and various kinds of pedagogical activities (including simply the provision of multiple examples in the input available to the learner) can be of benefit. PT holds that each stage is a prerequisite for the next one and that teaching two steps beyond the current stage has no effect; therefore, Stage 3 represents the outer bound of teachability or, in other words, of the learner's ZPD, and Stage 4 is outside the ZPD because it is not amenable to instruction. 


\section{Conclusion}

In this paper, I have outlined briefly a reason why representing mainstream SLA theory in terms of SCT may be desirable and how that might be done. Space considerations preclude a fuller explanation of how this will benefit the field as well as potential answers to possible objections to such an enterprise, which will be the subject matter of a forthcoming paper.

Figure 3. Pienemann's (2009) four stages of question formation mapped onto a ZPD framework.

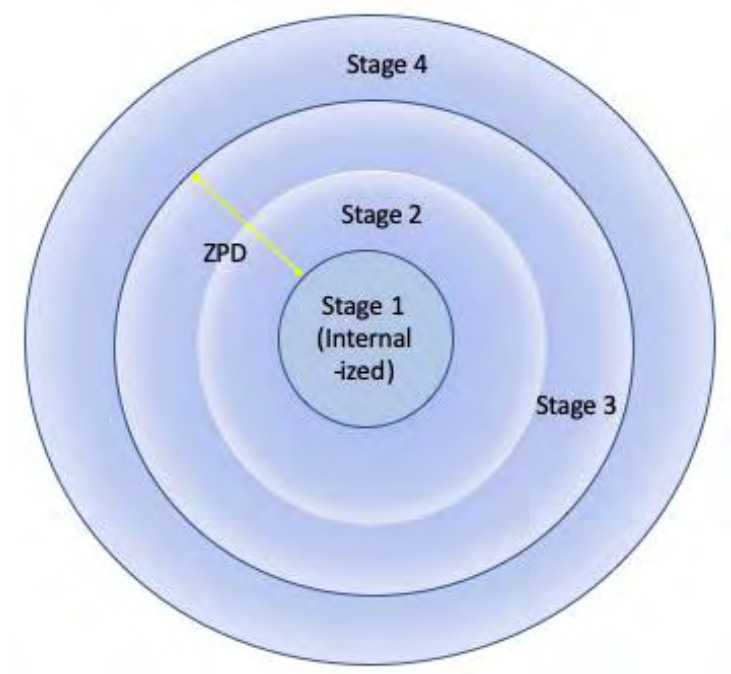

\section{References}

Aljaafreh, A., \& Lantolf, J. P. (1994). Negative feedback as regulation and second language learning in the zone of proximal development. The Modern Language Journal, 78(4), 465-483. http://doi.org/10.1111/j.1540-4781.1994.tb02064.x

Guk, I., \& Kellogg, D. (2007). The ZPD and whole class teaching: Teacher-led and student-led interactional mediation of tasks. Language Teaching Research, 11(3), 281-299. doi:10.1177/1362168807077561

Lantolf, J. P., \& Thorne, S. L. (2007). Sociocultural theory and second language learning. In B. VanPatten \& J. Williams (Eds.), Theories in second language acquisition: An introduction (pp. 201-224). Mahwah, NJ: Lawrence Erlbaum.

Lavin, R. S., \& Nakano, Y. (2017). Visualizing the concept of the ZPD in language education. The Journal of the Graduate School of Language \& Literature, Prefectural University of Kumamoto, 10, 39-51.

Ohta, A. S. (2001). Second language acquisition processes in the classroom: Learning Japanese. Mahwah, NJ: Routledge.

Pienemann, M. (1998). Language processing and second language development. Amsterdam, The Netherlands: John Benjamins Publishing.

Pienemann, M. (2009). An introduction to Processability Theory. In F. Mansouri (Ed.), Second language acquisition research: Theory-construction and testing (pp. 13-38). Newcastle upon Tyne, UK: Cambridge Scholars Publishing.

Pienemann, M. (2013). Processability Theory and teachability. In C. A. Chapelle (Ed.), The encyclopedia of applied linguistics (pp. 1-6). Oxford, UK: Blackwell Publishing. http://doi.org/10.1002/9781405198431.wbeal0958

Selinker, L. (1972). Interlanguage. International Review of Applied Linguistics, 10, 209-231.

Selinker, L. (2014). Interlanguage 40 years on: Three themes from here. In Z. Han \& E. Tarone (Eds.), Interlanguage: Forty years later (pp. 221-246). John Benjamins.

VanPatten, B., \& Williams, J. (2007a). Introduction: The nature of theories. In B. VanPatten \& J. Williams (Eds.), Theories in second language acquisition: An introduction (pp. 1-16). Mahwah, NJ: Lawrence Erlbaum.

VanPatten, B., \& Williams, J. (Eds.). (2007b). Theories in second language acquisition: An introduction. Mahwah, NJ: Lawrence Erlbaum.

Vygotsky, L. S. (1978). Mind in society. Cambridge, MA: Harvard University Press. 